\title{
HUBUNGAN KUALITAS PENGAWASAN KEPALA SEKOLAH TERHADAP KOMPETENSI PEDAGOGIK
}

\author{
I Gede Nuarta \\ TK Negeri Desa Joanyar \\ e-mail: nuartaig212@gmail.com
}

\begin{abstract}
Abstrak
Rancangan penelitian yang digunakan dalam penelitian ini adalah rancangan expost facto. Dalam penelitian ini populasinya adalah seluruh guru yang ada di TK Negeri Desa Joanyar yang berjumlah 4 orang. Teknik sampling yang dipergunakan dalam penentuan sampel adalah Proportional Random Sampling. Proporsional yang dimaksud adalah pengambilan sampel sesuai dengan proporsi. Data yang dikumpulkan dalam penelitian ini yaitu 1) kompetensi pedagogik guru-guru di TK Negeri Desa Joanyar. Data kompetensi pedagogik dikumpulkan menggunakan kuesioner, data pengelolaan pembelajaran guru-guru menggunakan tes observasi dan data kualitas pengawasan kepala sekolah dikumpulkan dengan kuesioner. Data yang diperoleh dianalisis dengan menggunakan statistik deskriptif. Hasil analisis menunjukkan bahwa Terdapat hubungan secara langsung dan tidak langsung antara kualitas pengawasan oleh kepala sekolah terhadap kompetensi pedagogik pada Guru di TK Negeri Desa Joanyar. Kontribusi kualitas pengawasan oleh kepala sekolahterhadap terhadap kompetensi pedagogik guru secara langsung dan tidak langsung sebesar $87,2 \%$.
\end{abstract}

Kata kunci: Kualitas Pengawasan, Kompetensi Pedagogik

\begin{abstract}
The study design used in this study was an ex post facto design. In this study the population is all teachers in the Joanyar Village State Kindergarten, which amounts to 4 people. The sampling technique used in sampling was Proportional Random Sampling. Proportion meant by sampling in proportion. The data collected in this study are 1) pedagogical competencies of teachers at the Joanyar Village State Kindergarten. Pedagogic competency data were collected using questionnaires, learning management data of teachers using observation tests and data on the quality of supervision of principals collected by questionnaire. The data obtained were analyzed using descriptive statistics. The results of the analysis show that there was a direct and indirect relationship between the quality of supervision by the principal to the pedagogic competence of the teacher at TK Negeri Desa Joanyar. The contribution of the quality of supervision by the principal towards the teacher's pedagogical competence directly and indirectly was $87.2 \%$.
\end{abstract}

Keywords: Quality of Supervision, Pedagogic Competence 


\section{Pendahuluan}

Reformasi pendidikan dalam upaya peningkatan kualitas pendidikan yang dilakukan pemerintah tidak terlepas dari peran guru sebagai unsur utama pelaksana pendidikan. Dalam proses pendidikan, guru tidak hanya berperan sebagai pengajar melainkan juga sebagai pendidik. Sebagai pengajar, guru bertugas menuangkan sejumlah bahan pelajaran ke dalam otak anak didik dengan kata lain guru mentransfer ilmu pengetahuan kepada peserta didiknya yang lebih menitikberatkan pada kemampuan pedagogik siswa. Namun, sebagai pendidik guru bertugas membimbing dan membina kemampuan bersosialisasi, spritual, serta sikap anak didik agar menjadi manusia susila yang cakap, aktif, kreatif, dan mandiri. Djamarah (2000) berpendapat bahwa baik mengajar maupun mendidik merupakan tugas dan tanggung jawab guru sebagai tenaga profesional. Oleh sebab itu, tugas yang berat dari seorang guru ini pada dasarnya hanya dapat dilaksanakan oleh guru yang memiliki profesionalisme yang tinggi.

Nanum dalam perjalanannya tidak ada satu institusipun yang melakukan evaluasi, apakah kesepuluh kompetensi guru ini betul-betul dipenuhi oleh guru atau tidak. Kesepuluh kompetensi ini hanya ada sebagai dokumen saja. Selama ini guru belum mampu menerapkan secara maksimal kesepuluh kompetensi tersebut.

Menurut Undang-undang juga disebutkan bahwa tujuan pendidikan adalah untuk berkembangnya potensi peserta didik agar menjadi manusia yang beriman dan bertaqwa terhadap Tuhan Yang Maha Esa, berakhlak mulia, sehat, berilmu, cakap, kreatif, mandiri, dan menjadi warga negara yang demokratis serta bertanggung jawab. (UU No 20 Th 2003). Proses pendidikan yang dilaksanakan di sekolah didominasi oleh kegiatan belajar mengajar (92,6 \% dari seluruh waktu yang ada di sekolah ada pada proses belajar mengajar) dengan bimbingan guru. Oleh karena itu 92,6 \% pula keberhasilan pendidikan di sekolah secara logika akan ditentukan oleh kualitas kegiatan proses belajar megajar, sekalipun masih banyak faktor lain yang berpengaruh, dalam hal ini adalah guru sebagai peran utamanya. Kondisi kelas pada saat pembelajaran biasanya diciptakan suasana yang tenang, tertib tak ada kewenangan apapun dari siswa kecuali guru, siswa diupayakan menjadi pendengar yang setia, sedangkan guru disiapkan untuk menjadi pembicara yang hebat, sedangkan buku, peraga dan media pembelajaran lain tidak banyak diperankan.

Menurut Susilowati (2013) Kompetensi diartikan sebagai pengetahuan keterampilan dan nilai-nilai dasar yang direfleksikan dalam kebiasaan berpikir dan bertindak. Kompetensi yang dimiliki oleh setiap guru akan menunjukkan kualitas guru yang sebenarnya. Standar kompetensi guru adalah suatu ukuran yang ditetapkan atau dipersyaratkan dalam bentuk penguasaan pengetahuan dan perilaku perbuatan bagi seseorang guru agar berkelayakan untuk menduduki jabatan fungsional sesuai bidang tugas, kualifikasi dan jenjang pendidikan. Menurut Habibullah (2012) kompetensi guru dalam penelitian ini adalah seperangkat kewenangan, pengetahuan, dan kemampuan, serta perilaku yang harus dimiliki, dihayati, dikuasai, dan diaktualisasikan dalam melaksanakan tugas profesi sebagai guru Pendidikan Agama Islam. Kewenangan adalah pemenuhan persyaratan secara administratif, persyaratan teknis, persyaratan psikis, dan persyaratan fisik untuk menjadi guru. Pengetahuan adalah proses pengulangan dan ingatan terhadap bahan ajar yang harus dikuasai oleh guru. Sedangkan kemampuan adalah daya tangkap, pemahaman, penghayatan, dan keterampilan yang diperlihatkan guru dalam menjalankan tugas mengajarnya. Menurut Fitriani (2017) Kompetensi guru diartikan sebagai penguasaan terhadap suatu tugas (mengajar dan mendidik), keterampilan, sikap, dan apresiasi yang diperlukan untuk menunjang keberhasilan proses pembelajaran yang dilakukannya. Dengan demikian, kompetensi yang dimiliki oleh setiap guru akan menunjukkan kualitas guru yang sebenarnya. Kompetensi tersebut akan diwujudkan dalam bentuk penguasaan ketrampilan, pengetahuan maupun sikap profesional dalam menjalankan tugas dan fungsi sebagai guru. Kompetensi Guru merupakan seperangkat pengetahuan, keterampilan, dan perilaku yang harus dimiliki, dihayati, dikuasai, dan diaktualisasikan oleh Guru dalam melaksanakan tugas keprofesionalan. Berdasarkan Peraturan Pemerintah (PP) Nomor 18 Tahun 2007 tentang 
Guru, dinyatakan bahwasanya kompetensi yang harus dimiliki oleh Guru meliputi kompetensi pedagogik, kompetensi kepribadian, kompetensi sosial, dan kompetensi profesional yang diperoleh melalui pendidikan profesi. Kompetensi Guru tersebut bersifat menyeluruh dan merupakan satu kesatuan yang satu sama lain saling berhubungan dan saling mendukung. Kompetensi Pedagogik yang dimaksud dalam tulisan ini yakni antara lain kemampuan pemahaman tentang peserta didik secara mendalam dan penyelenggaraan pembelajaran yang mendidik. Pemahaman tentang peserta didik meliputi pemahaman tentang psikologi perkembangan anak. Sedangkan Pembelajaran yang mendidik meliputi kemampuan merancang pembelajaran, mengimplementasikan pembelajaran, menilai proses dan hasil pembelajaran, dan melakukan perbaikan secara berkelanjutan.

Berbagai permasalahan pembelajaran yang sering dikeluhkan masyarakat seperti rendahnya minat guru dalam mengajar, ketidakmampuan guru mengatasi kesulitan menyusun dokumen-dokumen pembelajaran, kesulitan guru melaksanakan tugas mengajar menggunakan keterampilan mengajar yang sesuai dengan tuntutan materi pelajaran, ada guru yang selalu ketinggalan informasi pembaharuan bidang pembelajaran, kurangnya koordinasi antar kolega, model, dan strategi pembelajaran yang tidak efektif dan permasalahan lain yang berkaitan dengan pembelajaran.

Kompetensi Pedagogik sering tidak dipahami dan dimengerti oleh beberapa guru, tidak sedikit guru yang hanya mengajar saja tanpa mau tahu apa itu Kemampuan paedagogik adalah kemampuan dalam pembelajaran atau pendidikan yang memuat pemahaman terhadap hal-hal yang berkaitan dengan sifat peserta didik, ciri pesrta didik, perkembangannya peserta didik, konsep pendidikan yang berguna untuk membantu siswa,metodologi mengajar yang sesuai dengan bahan dan perkembangan siswa dan lainlain. Guru diharapkan memahami sifat-sifat, karakter, tingkat pemikiran, perkembangan fisik dan psikis anak didik. Dengan mengerti hal-hal itu guru akan mudah mengerti kesulitan dan kemudahan anak didik dalam belajar dan mengembangkan diri sehingga guru akan lebih mudah membantu siswa berkembang. Untuk itu diperlukan pendekatan yang baik, tahu ilmu psikologi anak dan perkembangan anak dan tahu bagaimana perkembangan pengetahuan anak.

Pentingnya seorang guru memiliki kompetensi pedagogik adalah guru dapat mengembangkan kemampuannya anak didiknya dengan maksimal karena guru yang menguasai beberapa teori tentang pendidikan dengan mengerti bermacam-macam teori pendidikan dapat memilih mana yang paling baik untuk membantu perkembangan anak didik. Selain itu Guru juga diharapkan memahami bermacam-macam model pembelajaran. Dengan semakin mengerti banyak model pembelajaran, maka dia akan lebih mudah mengajar pada anak sesuai dengan situasi anak didiknya. Pada dasarnya peningkatan kompetensi pedagogik guru akan menghindarkan kegiatan pembelajaran bersifat monoton ,tidak disukai siswa dan membuat siswa kehilangan minat serta daya serap dan konsentrasi belajarnya.

Meskipun pada kenyataannya tidak semua suasana kelas tersebut tercipta oleh setiap guru yang mengajar, bahkan kadang-kadang suasana menjadi sebaliknya yaitu suasana kelas gaduh, banyak siswa berbicara sendiri- sendiri, banyak yang tidak membawa buku dan sebahgainya, dan tidak sedikit guru yang menyerah pada kondisi seperti ini dengan cara meninggalkan kelas dan memberikan catatan atau tugas kepada siswanya. Akibat dari kondisi kelas yang kurang kondusif dalam pembelajaran maka berdampak pada tujuan belajar, guru, siswa maupun proses pembelajaran itu sendiri antara lain: 1) Guru menjadi jenuh tidak bersemangat dalam mengajar. 2) Siswa tidak kreatif yang berakibat rendahnya imaginasi dan idea pada siswa, 3) Siswa timbul kebosanan dalam belajar dan cenderung mengantuk, atau bermain sendiri atau ada yang tertekan. 4) Pembelajaran tidak mencapai tujuan (tidak efektif).

Pada dasarnya tingkat Kompetensi Pedagogik guru dipengaruhi oleh faktor dari dalam guru itu sendiri yaitu bagaimana guru bersikap terhadap pekerjaan yang diemban. Sedangkan faktor luar yang diprediksi berpengaruh terhadap kompetensi profesional seorang guru yaitu kepemimpinan kepala sekolah, karena kepala sekolah merupakan 
pemimpin guru di sekolah. Sikap guru terhadap pekerjaan merupakan keyakinan seorang guru mengenai pekerjaan yang diembannya, yang disertai adanya perasaan tertentu, dan memberikan dasar kepada guru tersebut untuk membuat respons atau berperilaku dalam cara tertentu sesuai pilihannya. Sikap guru terhadap pekerjaan mempengaruhi tindakan guru tersebut dalam menjalankan aktivitas kerjanya. Bilamana seorang guru memiliki sikap positif terhadap pekerjaannya, maka guru akan menjalankan fungsi dan kedudukannya sebagai tenaga pengajar dan pendidik di sekolah dengan penuh rasa tanggung jawab.

Sedangkan berdasarkan hasil diskusi dengan guru-guru, pemahaman guru di TK Negeri Desa Joanyar tentang kegiatan supervisi baik yang dilakukan oleh pengawas sekolah maupun kepala sekolah (1) diidentikkan dengan evaluasi, sehingga guru dilatih cenderung resah tetapi menerima supervisi tersebut karena merupakan program dari atasan, (2) pelaksanaan supervisi selama ini sifatnya mencari kelemahan para guru, sehingga para guru merasa was-was bila didatangi supervisor, (3) sasaran pengamatan yang dilakukan supervisor terlalu luas dan bersifat umum sehingga sukar memberikan balikan yang terarah dan bermanfaat bagi pembelajaran siswa di kelas, (4) umpan balik hanya bersifat pengarahan yang mengedapankan power, bahkan serangkaian instruksi yang berbau ancaman, dan tidak melibatkan guru dalam menganalisis dirinya untuk mencari cara mengembangkan dirinya serta tidak menemukan cara mengatasi kesulitan guru dalam mengajar. (5) supervisor jarang memonitoring keberadaan proses belajar di dalam kelas, hanya mengandalkan laporan dokumen yang diberikan guru.

Berdasarkan uraian di atas, dapat disimpulkan bahwa pendekatan supervisi klinis diduga mempengaruhi Kemampuan kompetensi pedagogik. Namun, seberapa jauh pengaruh pendekatan supervisi klinis terhadap Kemampuan kompetensi pedagogik belum dapat diungkapkan. Oleh sebab itu penulis tertarik untuk mengkaji secara ilmiah melalui penelitian dengan judul "Hubungan Kualitas Pengawasan Kepala Sekolah Terhadap Kompetensi Pedagogik guru di TK Negeri Desa Joanyar"

\section{Metode}

Penelitian ini merupakan penelitian expost facto. Rancangan penelitian yang digunakan dalam penelitian ini adalah rancangan expost facto. Metode survei dirancang untuk memperoleh informasi tentang status gejala pada saat penelitian dilakukan dengan tujuan untuk melukiskan variabel atau kondisi apa yang ada daiam suatu situasi. Variabel eksogen yang dijadikan objek dalam penelitian ini adalah Kualitas Pengawasan oleh Kepala Sekolah, sedangkan variabel endogennya adalah kompetensi pedagogik. Dalam penelitian ini populasinya adalah seluruh guru yang ada di TK Negeri Desa Joanyar. Pemilihan guruguru di TK Negeri Desa Joanyar sebagai populasi didasari oleh suatu pemikiran bahwa jarak antara lokasi penelitian dengan rumah peneliti sangat dekat sehingga memudahkan untuk mengadakan penelitian dan memudahkan menggali informasi yang diperlukan dalam penelitian. Sedangkan populasi target dalam penelitian ini adalah sebagian guru guru yang ada di TK Negeri Desa Joanyar. Teknik sampling yang dipergunakan dalam penentuan sampel adalah Proportional Random Sampling. Proporsional yang dimaksud adalah pengambilan sampel sesuai dengan proporsi (yaitu tiap sekolah).

Data yang dikumpulkan dalam penelitian ini meliputi: 1) Kompetensi Pedagogik guruguru di TK Negeri Desa Joanyar, 2) Kualitas Pengawasan Kepala Sekolah. Untuk mengetahui kualitas isi instrumennya, terlebih dahuu dilakukan uji validitas isi (uji pakar). Kriteria yang digunakan sebagai pedoman validitas isi instrument hasil belajar terdapat pada Tabel 1. 
Tabel 1. Rentangan Skor Validitas Isi Instrumen Penelitian

\begin{tabular}{ll}
\hline Koefisien & \multicolumn{1}{c}{ Validitas } \\
\hline $0,80-1,00$ & Validitas isi sangat tinggi \\
$0,60-0,79$ & Validitas isi tinggi \\
$0,40-0,59$ & Validitas isi sedang \\
$0,20-0,39$ & Validitas isi rendah \\
$0,00-0,19$ & Validitas isi sangat rendah \\
\hline
\end{tabular}

Rumus korelasi yang digunakan untuk menguji validitas item adalah rumus korelasi product moment dengan angka kasar. $r_{x y}>0,30$ berarti valid (dapat langsung digunakan), $0,20 \leq r_{x y} \leq 0,30$, berarti valid tetapi harus direvisi kembali, $r_{x y} \leq 0,20$ berarti tidak valid (gugur)

\section{Hasil dan Pembahasan}

Berdasarkan hasil analisis data harga-harga yang akan di sajikan setelah diolah dari data mentah dengan menggunakan metode deskriptif yaitu: Rata-rata, Median, Modus, Standar Deviasi, Varian, Minimum, Maximum, dan Jangkauan serta grafik histogram.Adapun deskripsi pada kedua kelompok disajikan pada Tabel 2.

Tabel 2. Deskripsi Data Kualitas Pengawasan oleh Kepala Sekolah

\begin{tabular}{cc}
\hline Statistik & Kualitas Pengawasan oleh Kepala Sekolah Siswa \\
\hline Rata-rata & 135.8 \\
Median & 135 \\
Modus & 140 \\
Standar Deviasi & 10.5323 \\
Varian & 110.9294 \\
Minimum & 109 \\
Maksimum & 157 \\
Jangkauan & 48 \\
\hline
\end{tabular}

Berdasarkan Tabel 2, data kualitas Pengawasan oleh Kepala Sekolah mempunyai skor minimum 48 dan skor maksimum 109 sehingga jangkauan skornya 157. Data skor kualitas Pengawasan oleh Kepala Sekolah dapat ditampilkan dalam bentuk tabel frekuensi. Untuk keperluan itu, maka terlebih dahulu dicari banyak kelompok interval $(k)=1+3,3$ Log $n$ $=1+3,3 \log (35)=6,09 \approx 6$ kelompok interval. Sedangkan panjang interval dapat ditentukan $(\mathrm{i})=\frac{\text { jangkauan }}{\mathrm{k}}=\frac{48}{6,09}=7,88 \approx 8$. Dengan demikian dapat ditampilkan tabel frekuensi data kualitas Pengawasan oleh Kepala Sekolah seperti Tabel 3.

Tabel 3. Distribusi Frekuensi dan Persentase Skor Kualitas Pengawasan

\begin{tabular}{ccc}
\hline \multirow{2}{*}{ Interval } & \multicolumn{2}{c}{ Kuasa kepemimpinan kepala sekolah } \\
\cline { 2 - 3 } & Fo & Persentase (\%) \\
\hline $109-117$ & 1 & 2.86 \\
$118-126$ & 4 & 11.43 \\
$127-135$ & 13 & 37.14 \\
$136-144$ & 10 & 28.57 \\
$145-153$ & 4 & 11.43 \\
$154-162$ & 3 & 8.57 \\
\hline Jumlah & $\mathbf{3 5}$ & $\mathbf{1 0 0 \%}$ \\
\hline
\end{tabular}


Berdasarkan Tabel 3, dapat diketahui bahwa skor kualitas Pengawasan oleh Kepala Sekolah sebagian besar berada pada interval 127 - 135.

Deskripsi data Kualitas pengelolaan pembelajaran memaparkan Rata-rata, Median, Modus, Standar Deviasi, Varian, Minimum, Maximum, dan Jangkauan. Deskripsi ini dikerjakan dengan bantuan program Pengolah Angka Microsoft Excell 2007. Hasil deskripsi data Kualitas pengelolaan pembelajaran dapat dilihat pada Tabel 04.

Deskripsi data kompetensi pedagogik guru memaparkan Rata-rata, Median, Modus, Standar Deviasi, Varian, Minimum, Maximum, dan Jangkauan. Deskripsi ini dikerjakan dengan bantuan program Pengolah Angka Microsoft Excell 2007. Hasil deskripsi data kompetensi pedagogik guru dapat dilihat pada Tabel 4.

Tabel 4. Deskripsi Umum Data Kompetensi pedagogik guru Siswa

\begin{tabular}{cc}
\hline Statistik & Kompetensi pedagogik guru \\
\hline Rata-rata & 146.83 \\
Median & 146 \\
Modus & 100 \\
Standar Deviasi & 19.64 \\
Varian & 385.56 \\
Minimum & 100 \\
Maksimum & 178 \\
Jangkauan & 78 \\
\hline
\end{tabular}

Berdasarkan Tabel 4, data kompetensi pedagogik gurumempunyai skor minimum 100 dan skor maksimum 178 sehingga jangkauan skornya 78. Data skor kompetensi pedagogik gurudapat ditampilkan dalam bentuk tabel frekuensi. Untuk keperluan itu, maka terlebih dahulu dicari banyak kelompok interval $(k)=1+3,3 \log n=1+3,3 \log (35)=6,09 \approx 6$ kelompok interval. Sedangkan panjang interval dapat ditentukan $(\mathrm{i})=\frac{\text { jangkauan }}{\mathrm{k}}=\frac{78}{6,09}=$ $12,80 \approx 13$. Dengan demikian dapat ditampilkan tabel frekuensi data kompetensi pedagogik guruseperti Tabel 5.

Tabel 5. Distribusi Frekuensi dan Persentase Skor Kompetensi Pedagogik Guru

\begin{tabular}{ccc}
\hline \multirow{2}{*}{ Interval } & & Kompetensi pedagogik guru \\
\cline { 2 - 3 } & Fo & Persentase (\%) \\
\hline $110-113$ & 2 & 5.71 \\
$114-127$ & 3 & 8.57 \\
$128-141$ & 7 & 20.00 \\
$142-155$ & 10 & 28.57 \\
$156-169$ & 9 & 25.71 \\
$170-183$ & 4 & 11.43 \\
Jumlah & $\mathbf{3 5}$ & $\mathbf{1 0 0 \%}$ \\
\hline
\end{tabular}

Berdasarkan Tabel 5, dapat diketahui bahwa skor kompetensi pedagogik guru sebagian besar berada pada interval 142 - 155.

Berdasarkan hasil analisis jalur antara Kualitas pengelolaan pembelajaran dengan kompetensi pedagogik guru didapatkan koefisien ( $r$ ) sebesar 0,872. Dimana pengaruh variabel $\mathrm{X} 1$ terhadap variabel y besarnya 0,872 yang terkomposisi menjadi pengaruh langsung dan pengaruh tidak langsung. Ini berarti bahwa sekitar 87,2\% kompetensi pedagogik guru siswa dapat dipengaruhi secara langsung dan tidak langusng oleh kualitas Pengawasan oleh Kepala Sekolah. 
Terdapat dua sub bagian yang akan dipaparkan pada bagian pembahasan ini, yaitu (1) hubungan antara kualitas Pengawasan oleh Kepala Sekolah dengan kompetensi pedagogik guru, (2) Hubungan antara kualitas Pengawasan oleh Kepala Sekolah dengan kompetensi pedagogik guru.

Berdasarkan hasil analisis regresi linear sederhana antara Kualitas pengelolaan pembelajaran dengan kompetensi pedagogik guru siswa dengan menggunakan bantuan program SPPS 10.0 for windows, didapatkan koefisien korelasinya ( $r$ ) sebesar 0,604. Dengan demikian dapat ditentukan besar koefisien determinasi antara Kualitas pengelolaan pembelajaran dengan kompetensi pedagogik guru $\left(r^{2}\right)$ sebesar 0,365. Ini berarti bahwa sekitar 36,5\% kompetensi pedagogik gurudapat dipengaruhi oleh Kualitas pengelolaan pembelajaran guru. Berdasarkan hasil analisis, dapat juga ditentukan persamaan regresi linear sederhana antara Kualitas pengelolaan pembelajaran dengan kompetensi pedagogik guruyaitu $Y=46,680+0,656 X_{2}$, di mana $\mathrm{Y}$ adalah kompetensi pedagogik gurudan $\mathrm{X}_{2}$ adalah Kualitas pengelolaan pembelajaran guru.

Untuk pengujian hipotesis penelitian, menggunakan angka signifikansi yang dihasilkan dari analisis regresi linear sederhana dengan menggunakan bantuan program SPSS 10.0 for windows. Jika angka signifikansi Regression hasil SPSS lebih kecil dari angka signifikansi yang ditetapkan yakni 0,05 maka $\mathrm{H}_{0}$ ditolak atau $\mathrm{H}_{1}$ diterima. Berdasarkan hasil analisis, untuk hubungan antara Kualitas pengelolaan pembelajaran dengan kompetensi pedagogik guru dapat diketahui nilai $F=40,733$ dan angka signifikansi regression $=0,001$. Angka signifikansi ini lebih kecil dari 0,05 sehingga $\mathrm{H}_{0}$ ditolak atau $\mathrm{H}_{1}$ diterima yang berarti terdapat hubungan yang signifikan antara Kualitas pengelolaan pembelajaran dengan kompetensi pedagogik guru Kelas.

\section{Simpulan dan Saran}

Berdasarkan hasil analisis dan pembahasan, simpulan yang dapat ditarik dari penelitian ini adalah sebagai berikut. Terdapat hubungan yang signifikan antara kualitas pengawasan oleh kepala sekolah terhadap kompetensi pedagogik guru sebesar $5,4 \%$. Terdapat hubungan yang signifikan antara kualitas pengelolaan pembelajaran terhadap kompetensi pedagogik guru kelas di TK Negeri Desa Joanyar. Kontribusi kualitas pengelolaan pembelajaran guru terhadap kompetensi pedagogik guru sebesar $36, \%$. Terdapat hubungan secara langsung dan tidak langsung antara kualitas pengawasan oleh kepala sekolah terhadap kompetensi pedagogik guru kelas di TK Negeri Desa Joanyar. Kontribusi kualitas pengawasan oleh kepala sekolah terhadap terhadap kompetensi pedagogik guru secara langsung dan tidak langsung sebesar $87,2 \%$.

Berdasarkan hasil penelitian ini, maka dapat diajukan beberapa saran guna peningkatan kompetensi pedagogik guru ke depan. Hasil penelitian menunjukkan bahwa terdapat hubungan yang signifikan antara kualitas pengawasan oleh kepala sekolah dengan kompetensi pedagogik guru. Untuk itu, para kepala sekolah atau pimpinan sekolah hendaknya menggunakan kuasa kepemimpinannya untuk memberikan motivasi atau semangat dalam mengembangkan pembelajaran yang inovatif di kelas untuk meningkatkan kompetensi pedagogik guru sehingga profesionalisme guru dapat ditingkatkan. Bagi guru disarankan untuk dapat mengembangan pembelajaran di kelas yang lebih inovatif lagi sehingga proses pembelajaran menjadi lebih aktif dan menyenangkan. Bagi peneliti lain yang berminat terhadap temuan penelitian ini dapat melakukan pembuktian-pembuktian yang lebih mendalam dengan mengambil populasi dan sampel yang lebih besar.

\section{Daftar Rujukan}

Arikunto, Suharsini. 2009. Dasar-dasar Evaluasi Pendidikan. Jakarta: Bumi Aksara.

Arsyad, A. 2009. Media Pembelajaran. Jakarta: PT Raja Grafindo. 
Ridwan \& Akdon. 2010. Rumus dan Data dalam Aplikasi Statistika. Bandung: Alfabeta.

Benham, H. C. (2002). Training effectiveness, online delivery and the influence of learning style. Paper presented at the 2002 ACM SIGCPR Conference on Computing Personal Research, Kristiansand, Norway.

Borg, Walter R. and Meredih D. Gall. 1989. EducationResearch. New York: Longham.

Borg, Walter R. and Meredih D. Gall. 2003. Education Research an Introduction. New York: Von Hoffman Press, Inc.

BSNP. 2006. Standar Kompetensi dan Kompetensi Dasar SD/MI. Jakarta: BSNP.

Candiasa, I.M. 2004. Analisis BUTIR Disertai Aplikasi dengan ITEMAN, BIGSTEPS dan SPSS. Singaraja: Unit Penerbitan IKIP Negeri Singaraja.

Candiasa, I.M. 2007. Statistik Multivariat Disertai Petunjuk dengan SPSS. Singaraja: Program Pascasarjana, Universitas Pendidikan Ganesha.

Dantes, Nyoman. 2001. Cara Pengujian Alat Ukur. Singaraja: IKIP Singaraja.

Dantes, Nyoman. 2008.Supervisi Akademik dalam Kaitannya Dengan Penjaminan Mutu Pendidikan (Makalah).

Fitriani, Cut, Murniati AR, Nasir Usman. 2017. Kompetensi Profesional Guru Dalam Pengelolaan Pembelajaran di MTS Muhammadiyah Banda Aceh. Jurnal Magister Administrasi Pendidikan Pascasarjana Universitas Syiah Kuala Vol. 5 No. 2 Hal. 8895. Tersedia Pada : http://www.jurnal.unsyiah.ac.id/JAP/article/view/8246.

Goll, Meredith D., Jayce P. Gall, Walter R. Borg. 2003. Educational Reseach. Boston: Longman, Pearson.

Gregory, Robet J. 2000. Psychological Testing (History Principles, and Applications). Bonston : Allyn and Bacon.

Guilford. 1959. Fundamental Statistics in psychology and Education: Third Edition. Tokyo: Kogakusha Company, Ltd.

Habibullah, Achmad. 2012. Kompetensi Pedagogik Guru. Edukasi Volume 10, Nomor 3, Hal. 362-377. Tersedia Pada https://jurnaledukasikemenag.org/index.php/edukasi/article/view/169.

Hamzah B.Uno \& Kudrat Umar, Masri. 2009. Mengelola Kecerdasan dalam Pembelajaran "Sebuah Konsep Pembelajarn Berbasis Kecerdasan". Jakarta: Bumi Aksara.

Honey dan Mumford (1992) Honey, P., \& Mumford, A. (1992). The Manual of Learning Styles (3rd ed.).Maidenhead, UK: Peters Honey.

James, W. B., \& Blank, W. E. (1993). Review and critique of available learningstyle instruments for adults. In D. Flannery (Ed.), Applying cognitive learning styles San Francisco: Jossey-Bass.

Koyan, I Wayan. 2011. Asesmen dalam Pendidikan. Singaraja: Universitas Pendidikan Ganesha Press. 
Ruseffendi, E.T. 2006. Pengajaran Matematika untuk Meningkatkan CBSA. Bandung: Tarsito.

McLoughlin, C. (1999). The implications of research literature on learning styles for the design of instructional material. Australian Journal of Educational Technology, 15(3).

Ridwan, dan Akdon. 2006. Rumus dan Data dalam Aplikasi Statistika. Bandung: Alfabeta.

Santyasa, I W. 2009. Metode penelitian tindakan kelas, pengembangan, korelasional, kausal komparatif, dan eksperimen. Makalah. Disajikan dalam Workshop tentang Penelitian Tindakan Kelas (PTK) bagi Para Guru SMP 2 dan 5 Nusa Penida Klungkung, tanggal 30 November s.d 1 Desember 2007, Nusa Penida, Klungkung.

Sumarna Surapranata. 2006. Analisis Validitas, Reabilitas, dan Interpretasi Hasil Tes: Implementasi Kurikulum 2004. Bandung: PT. Remaja Rosdakarya.

Susilowati, Indah, Himawan Arif Sutanto, Reni Daharti. 2013. Strategi Peningkatan Kompetensi Guru dengan Pendekatan Analysis Hierarchy Process. Journal of Economics and Policy Vol. 6 No. 1 Hal. 80-92. Tersedia Pada : https://journal.unnes.ac.id/nju/index.php/jejak/article/view/3750.

Sutrisno,Hadi. 1996. Metodologi Research IV. Andi Offset: Yogyakarta.

Syaiful Sagala. 2012. Konsep dan Makna Pembelajaran "Untuk Membantu Memecahkan Problematika Belajar dan Mengajar". Bandung: Alfabeta.

Trianto. 2007. Model Pembelajaran Terpadu dalam Teori dan Praktek. Jakarta: Prestasi Pustaka.

Wahidmurni, Alfin Mustikawan, Ali Ridho. 2010. Evaluasi Pembelajaran Kompetensi dan Praktik. Yogyakarta: Nuha Litera. 